\title{
Contemporary Catheter-Based Treatment Options for Management of Acute Pulmonary Embolism
}

Maninder Singh, MBBS $^{1}$

Irfan Shafi, $M D^{2}$

Parth Rali, $M D^{3}$

Joseph Panaro, $M D^{4}$

Vladimir Lakhter, $\mathrm{DO}^{1}$

Riyaz Bashir, MD ${ }^{1,5, *}$

\author{
Address \\ ${ }^{1}$ Department of Cardiovascular Disease, Temple University Hospital, Philadelphia, \\ PA, USA \\ ${ }^{2}$ Department of Internal Medicine, Wayne State University/DMC, Detroit, MI, USA \\ ${ }^{3}$ Department of Thoracic Medicine and Surgery, Temple University Hospital, Phil- \\ adelphia, PA, USA \\ ${ }^{4}$ Department of Radiology, Temple University Hospital, Philadelphia, PA, USA \\ ${ }^{*}, 5$ Division of Cardiovascular Diseases, Temple University Hospital, 3401 N. Broad \\ Street (9PP), Philadelphia, PA, 19140, USA \\ Email: Riyaz.Bashir@tuhs.temple.edu
}

Published online: 12 May 2021

(C) The Author(s), under exclusive licence to Springer Science+Business Media, LLC, part of Springer Nature 2021

This article is part of the Topical Collection on Vascular Disease

Keywords Acute pulmonary embolism • Endovascular therapy · Catheter-directed thrombolysis · COVID-19 • Pulmonary embolism response team

\section{Abstract}

Introduction Acute pulmonary embolism (PE) remains an important cause of cardiovascular mortality and morbidity in the USA and worldwide. Catheter-based therapies are emerging as a new armamentarium for improving outcomes in these patients.

Purpose of review The purpose of this review is to familiarize the clinicians with (1) various types of catheter-based modalities available for patients with acute PE, (2) advantages, disadvantages, and appropriate patient selection for the use of these devices, and (3) evidence base and the relevance of such therapies in the COVID-19 pandemic.

Recent findings There are four main types of catheter-based therapies in acute PE: (1) standard catheter-directed thrombolysis (CDT), (2) ultrasound-assisted CDT, (3) pharmacomechanical CDT, and (4) mechanical thrombectomy without thrombolysis. Ultrasound- 
assisted thrombolysis is the most widely studied modality in this group; however, evidence base for other catheter-based technologies is rapidly emerging.

Summary Current use of catheter-based therapies is most suitable for patients with intermediate and high-risk acute PE. The adoption of a multidisciplinary approach like the pulmonary embolism response team (PERT) is desirable for appropriate patient selection and possibly/potentially improving patient outcomes. We discuss the current status of these therapies.

\section{Introduction}

Acute pulmonary embolism (PE) is the third most common cause of cardiovascular death $[1 \bullet, 2]$, and venous thromboembolism (VTE) affects more than 500,000 people in the United States (US) alone annually [2]. In US, it causes approximately 100,000 deaths each year. Majority of deaths caused by acute PE are due to severe pulmonary vascular obstruction. Catheter-based therapies have recently emerged as an important tool in the treatment of PE patients, particularly the high-risk group. In this review, we discuss appropriate patient selection, types, and evidence base for currently available catheter-based technologies and the relevance/ utilization of these therapies in the COVID-19 pandemic.

\section{Pathophysiology of acute PE and clinical implications for catheter-based therapies}

While percutaneous catheter-based therapies are established as the firstline treatment approaches for thromboembolism in the arterial vasculature such as coronary thrombosis or cerebrovascular embolism, this is not yet true for pulmonary embolism. It is essential to highlight a few pathophysiological differences to fully appreciate the use and limitations of catheter-based therapies for these conditions.

Acute pulmonary embolism often is a result of embolization of thrombi originating in the lower extremity venous circulation which results from stasis and a hypercoagulable state [3] and tends to be occlusive [4]. Adverse hemodynamic consequences of acute pulmonary embolism are related to overall thrombus volume or burden. While small volume thrombi causing acute pulmonary embolism may be subclinical, patients with hemodynamic compromise due to acute PE tend to have a large thrombus volume or burden. These factors have important clinical implications in achieving adequate results with catheter-based therapies. Whereas large thrombus burden is often not amenable for complete resolution with a low dose of thrombolytic agents, adequate mechanical aspiration of thrombi from distal vessels remains also challenging, later being the most important element for reduction of dead space.

\section{Patient selection for catheter-based therapies}


Apart from systemic anticoagulation and supportive care, most of the high-risk and selected intermediate-risk patients require advanced therapeutic options targeting the pulmonary artery thrombus to achieve adequate pulmonary vascular reperfusion and reduction in afterload to the right ventricle (RV). Mortality benefit of systemic thrombolysis in patients with hemodynamic instability has been shown in multiple clinical trials and meta-analyses [5, 6] and is recommended as the first-line therapy (grade 2C) for patients with acute unstable PE by the American College of Chest Physicians (ACCP) - 2016 guidelines [7]. In the setting of persistent hemodynamic instability (defined as systolic blood pressure $<90 \mathrm{mmHg}$ ), the role of catheter-based therapies is limited to patients with high bleeding risk, those who fail systemic thrombolysis, or whose death is imminent before systemic thrombolytic therapy can take effect (grade 2C) [7]. While systemic thrombolysis is the choice of therapy for hemodynamically unstable or high-risk acute PE patients, clinical trials in intermediate-risk acute PE showed significantly higher bleeding rates (extracranial and intracranial hemorrhage rates of $6.3 \%$ and $2 \%$ respectively in the PEITHO trial), which reduced the overall net benefit of systemic thrombolysis [8].

Catheter-based therapies have emerged as the choice of treatment for patients presenting with intermediate-risk PE in the recent years. Intermediate-risk PE is more common compared to high-risk (massive) acute $\mathrm{PE}$, comprising nearly one third of all patients presenting with acute PE [9]. In addition to that, these patients remain at high risk for severe complications and progression to hemodynamic instability. In the placebo arm of the PEITHO trial [8], patients who were treated with anticoagulation alone, 4.6\%, (23/499) patients required rescue treatment with systemic thrombolytic therapy and more than $70 \%$ of those patients did not survive in spite of the rescue thrombolysis. In another randomized trial comparing alteplase with placebo in patients with submassive $\mathrm{PE}, 25 \%(34 / 138)$ of the patients in the placebo arm required escalation of treatment, with 23\% (32/138) requiring thrombolytic therapy during hospitalization [10]. In these patients, catheter-based therapies offer a potential clinical benefit without exposing the patients to the risk of high-dose systemic thrombolytic therapy. In the following sections, we discuss specific catheter-based therapies and clinical evidence for use in patients with intermediaterisk acute PE.

Ultrasound-assisted catheter-directed thrombolysis (CDT)

The use of CDT achieves thrombolysis using lower doses of fibrinolytic agents compared to systemic administration of these agents, which often require much higher doses. Due to the lower dose of the fibrinolytic agents, the risk of major or serious bleeding is lower. Although a few catheter devices have received 510(k) FDA approval, ultrasound-facilitated fibrinolysis (EkoSonic, Boston Scientific, Marlborough, MA) is the best-studied catheter in this category [11]. Ultrasound-facilitated thrombolysis relies on the principle of enhancing drug delivery into the thrombus using ultrasound energy [12]. The use of this catheter has been studied in three prospective trials [13, 14, 15•] (Table 1). The SEATTLE II [13] was a single-arm, prospective trial which included 150 patients. These patients underwent ultrasoundfacilitated thrombolysis with an infusion of $1 \mathrm{mg} / \mathrm{h}$ tPA for $24 \mathrm{~h}$ for one device in unilateral PE or $1 \mathrm{mg} / \mathrm{h}$ for $12 \mathrm{~h}$ (for two devices) for bilateral PEs. The primary outcome in the trial was a change in $\mathrm{RV} / \mathrm{LV}$ ratio $48 \mathrm{~h}$ post-CDT. There was a significant decrease in RV/LV ratio from 1.55 to $1.13(p<0.0001)$ 


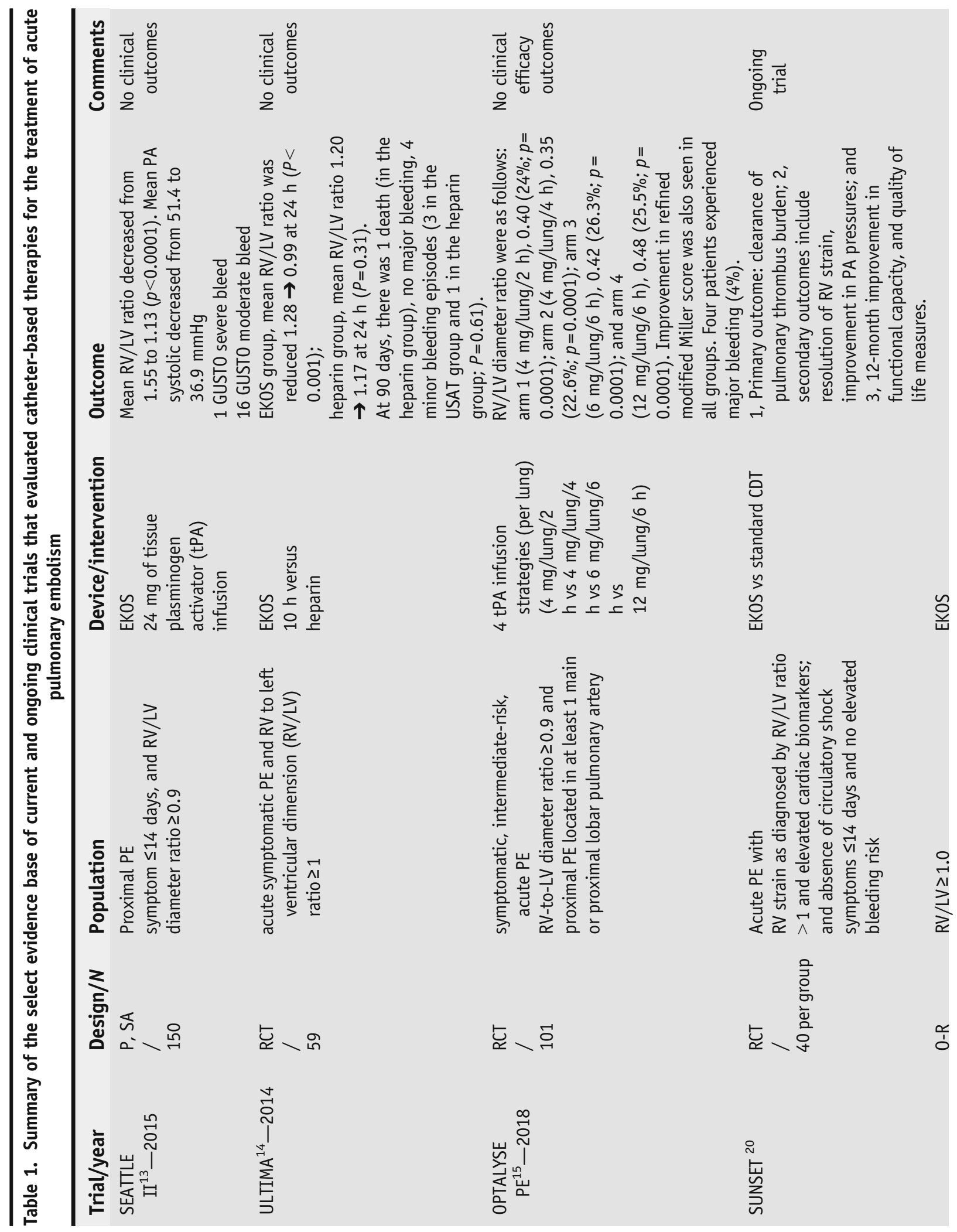




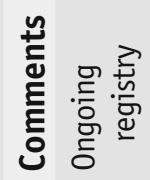

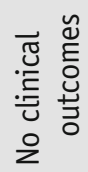

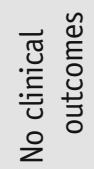



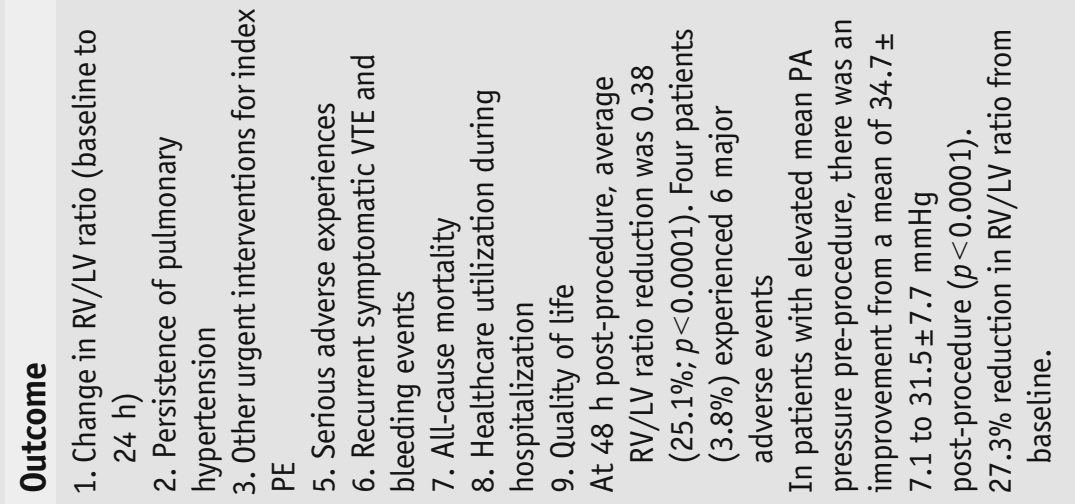

ō
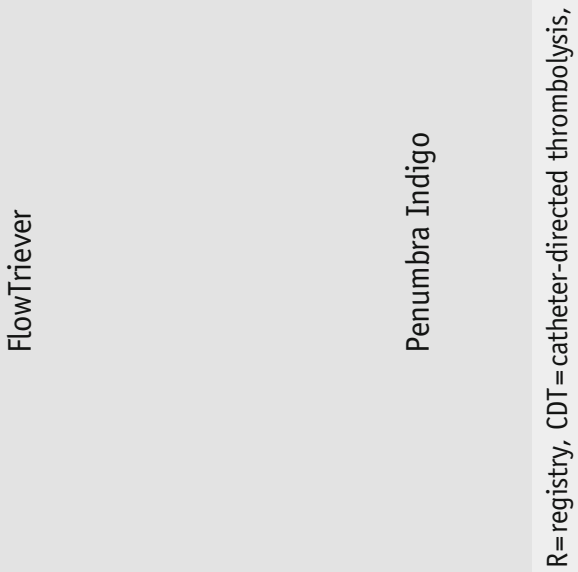

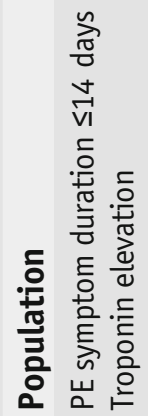
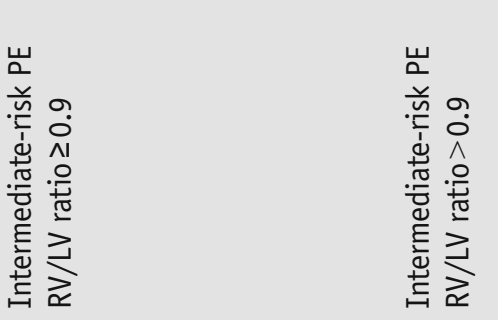

市

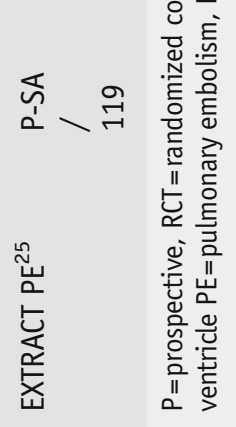


after CDT. There was a significant reduction (29\%) of thrombus burden as assessed by the modified Miller score. Another small randomized controlled trial of 59 patients compared ultrasound-accelerated thrombolysis versus heparin-alone infusion [14]. In this trial, CDT was associated with a greater reduction in $\mathrm{RV}$ size and RV/LV ratio at $24 \mathrm{~h}$ ( 0.30 versus 0.03 with heparin, $p<0.0001)$ and 90 days ( 0.38 versus 0.22 with heparin, $p=0.03)$. Another trial compared patients who were randomized to various doses of fibrinolytics for shorter durations (4 mg/lung/2 h vs $4 \mathrm{mg} / \mathrm{lung} / 4 \mathrm{~h}$ vs $6 \mathrm{mg} / \mathrm{lung} /$ $6 \mathrm{~h}$ vs $12 \mathrm{mg} / \mathrm{lung} / 6 \mathrm{~h}$ ) [15•]. It showed that lower doses were effective in improving RV size and function; however, the reduction in thrombus burden was poor at lower doses. There was a very clear dose-response relationship of tPA with thrombus burden reduction noted in this trial. We hope more insights will be available from an ongoing prospective registry; KNOCKOUT PE [16] is enrolling 1500 patients undergoing ultrasound-assisted CDT with EkoSonic catheter and plans to study clinical outcomes like mortality and quality of life.

Cragg-Mcnamara (Medtronic, Minneapolis, Minnesota), Unifuse (Angiodynamics, Latham, NY), and Fountain (Merritt Inc) catheters are other devices available for CDT. These catheters have multiple side slits, to facilitate the distribution of the fibrinolytic agent within the thrombus [17, 18]. The main advantage of these catheters over the ultrasound facilitated catheter is the lower cost. Comparison of these low-cost catheters with ultrasound facilitated thrombolysis is limited only to retrospective studies. A retrospective study, which included 98 cases, showed a similar degree of reduction in pulmonary artery pressures, RV/LV ratio, or hospital length of stay in both groups [19]. Another retrospective study which included 70 patients showed similar results [20]. SUNSET sPE trial is a randomized trial comparing outcomes in patients undergoing CDT using the EkoSonic catheter versus standard catheter-directed thrombolysis. There was no significant difference in the reduction in the mean obstruction index reduction ( $21 \%$ versus $22 \%, p=0.77$ ) or mean thrombus score reduction (post-CDT score $22 \pm 7$ versus $23 \pm 7, p=0.76$ ) between patients undergoing CDT using the EkoSonic versus the standard catheter device [21].

\section{Mechanical thrombectomy without thrombolysis}

The main advantage of mechanical thrombectomy over CDT is potentially the quicker reduction in pulmonary vascular obstruction and the ability to achieve this without using fibrinolytic agents. However, some of these advantages are offset by the need to place large-bore venous access cannulas for some device systems and the risk of distal embolization to normally functioning segments of the pulmonary circulation. Few devices are available in this category. Two important devices in this category that have received FDA clearance include the FlowTriever Retrieval/Aspiration system and the Penumbra Indigo aspiration catheter system. 
The FlowTriever Retrieval/Aspiration (Inari Medical, Inc., Irvine, California) catheter is available in three sizes $16 \mathrm{~F}, 20 \mathrm{~F}$, and $24 \mathrm{~F}$. In addition to the aspiration cannula, this system also has three nitinol mesh disks, which can be deployed beyond the thrombus and then retrieved in the aspiration catheter [22]. The safety and effectiveness of this catheter were tested in the FLARE trial, a prospective, single-arm trial, which enrolled 106 patients with acute intermediate-risk pulmonary embolism and right ventricular strain defined as $\mathrm{RV} / \mathrm{LV}$ ratio $\geq 0.9$. The primary end point was a change in $\mathrm{RV} / \mathrm{LV}$ ratio. There was a mean $\mathrm{RV} / \mathrm{LV}$ ratio reduction of $0.38(p<0.0001)$. One patient experienced a major bleeding event and four patients had other major complications (including pulmonary vascular injury in 1 patient, respiratory deterioration requiring emergent intubation in 2 patients, and ventricular fibrillation in 1 patient) during the procedure [23].

Another thrombectomy device, the Penumbra Indigo (Penumbra, Alame$\mathrm{da}, \mathrm{CA}$ ) aspiration catheter, is a continuous aspiration system, which requires an 8 French venous access sheath. The safety and efficacy of this device were evaluated in the EXTRACT PE trial. This trial enrolled 119 patients with intermediate-risk acute $P E$ and showed a significant reduction of mean RV/LV ratio at $48 \mathrm{~h}$. The median ICU length of stay was 1 day and $1.7 \%$ of the patients experienced major adverse events at $48 \mathrm{~h}$ including one device-related death [24]. While a smaller $8 \mathrm{~F}$ venous access sheath makes this device less prone to access site-related bleeding complications, it decreases the effectiveness for achieving adequate thrombectomy for some larger-sized proximal clots [25]. Another disadvantage associated with the use of aspiration devices is significant blood loss, often inevitable during aspiration of thrombi from the pulmonary vasculature. The new $12 \mathrm{~F}$ penumbra device has been recently developed; it uses an intelligent design and performs suction only when in contact with thrombus [26].

In addition to the above devices, some other devices have been used for thrombectomy with mixed results. Angiojet (Boston Scientific, Marlborough, Massachusetts) rheolytic thrombectomy device has been used in patients with high-risk and intermediate-risk acute PE patients. Data from a retrospective study, of 51 patients at a single center, showed that the use of Angiojet was feasible in patients presenting with acute PE [27]. However concerns with bradyarrhythmias, hypotension, and other complications associated with the use of Angiojet led to a black box warning from the FDA for use of this device $[25,28]$. The use of other devices such as rotating pigtail catheter with aspiration [29], Aspirex catheter (Straub Medical, Switzerland) [30], or the JETi thrombectomy device (Walk Vascular, Irvine, $\mathrm{CA}$ ) is mostly limited to case reports or small case series.

The pharmacomechanical approach to endovascular treatment of acute pulmonary embolism is based on the principle of delivering even lower doses of a fibrinolytic drug with mechanical thrombus fragmentation, to enhance the delivery of the fibrinolytic agent. The approach is commonly employed in the treatment of lower extremity deep venous thrombosis and has been studied in a randomized controlled trial [31]. However, the use of the pharmacomechanical approach in the treatment of acute PE is limited 
due to the lack of dedicated devices. Angiojet catheter can be used to deliver tPA during thrombectomy, but the use of this device was associated with a high rate of complications in a meta-analysis by Kuo and colleagues [28]. Another currently available catheter is the Bashir Endovascular catheter (BEC, Thrombolex, New Britain, PA) which is based on the principle of pharmacomechanical fragmentation and thrombolysis [32]. This catheter enhances the delivery of tPA by exposing a higher surface area of the thrombus and fibrin-binding sites for both endogenous and exogenous fibrinolytics, thus acting synergistically to enhance thrombus resolution. This catheter insertion requires a 7F venous access sheath. Once deployed within the thrombus, a nitinol reinforced basket at the tip of this catheter expands up to $45 \mathrm{~mm}$, which can then be collapsed and redeployed to increase surface area and binding sites for tPA within the thrombus. The device allows pulse sprays as well as the infusion (Fig. 1). The pulse spray with an expanded basket creates bubbles of tPA that are trapped inside a thrombus and continue to lyse the clot even after the device is removed from the body. The first in human feasibility study included 9 patients who underwent CDT using the BEC [33]. There was significant reduction in RV/ $\mathrm{LV}$ ratio from $1.52 \pm 0.26$ to $0.97 \pm 0.06(p=0.0009 ; 95 \% \mathrm{CI}=0.33$ to 0.82 ; $37.0 \%$ reduction), and thrombus burden from $25.4 \pm 5.3$ to $16.0 \pm 4.0$ ( $p=$ $0.0005 ; 95 \% \mathrm{CI}=5.5$ to $13.4 ; 37.1 \%$ reduction) as measured by the modified Miller index post-CDT compared to baseline. More insights will be available from the RESCUE trial (NCT03927508), a multicenter prospective study which is currently enrolling patients with intermediate-risk acute PE to assess the safety and efficacy of the BEC-directed thrombolysis [32].

\section{Inferior vena cava (IVC) filter for acute PE}

Another endovascular therapy to consider in patients with acute PE is the IVC filter. In patients with acute severe PE, but without any contraindications to anticoagulation, there was no benefit of routine use of IVC filter placement in addition to anticoagulation versus anticoagulation alone. The PREPIC-2 trial did not demonstrate any difference in recurrent PE between the two arms [34]. The results of this trial led to the ACCP guideline recommendation against routine use of IVC filter in patients with acute PE, but without any contraindications to anticoagulation use $[7,35]$.

While IVC filter is commonly used in patients with venous thromboembolism and perceived contraindications to anticoagulation, the benefit of IVC filter on reducing short-term mortality was noted only in patients with active bleeding in a large observational study from California [36]. The use of an IVF filter in patients with acute PE is intended to lower the risk of recurrent PE and further hemodynamic compromise. The evidence base for this particular scenario is mostly limited to observational or retrospective studies and is conflicting [36-38]. A case-control study by Gates and colleagues [37] evaluated the incidence of symptomatic PE in patients with venous thromboembolism and high risk for PE who 

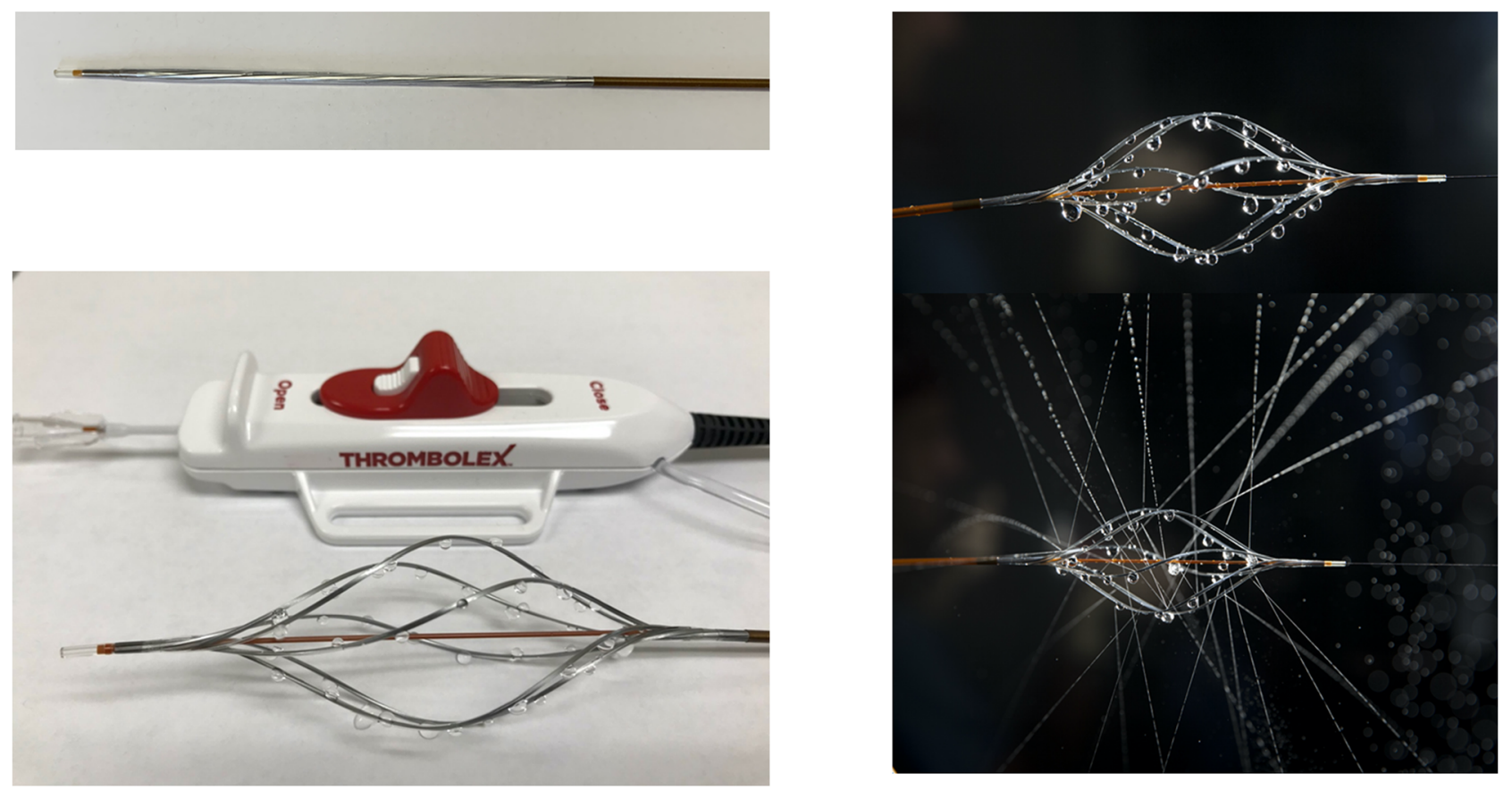

Fig. 1. Bashir endovascular catheter device.

underwent IVC filter placement due to a perceived contraindication to anticoagulation. There was no difference in the incidence of symptomatic PE between patients with or without IVC filter. Moreover, majority of the patients who were perceived to have contraindication to anticoagulation use received anticoagulant therapy in this study. In the absence of highquality studies, a recent guideline document from the Society of Interventional Radiology [39] recommends the use of IVC filter placement in patients with acute PE and contraindications to anticoagulation, after careful consideration of risks and benefits of the use of IVF filter.

The use of IVC filter in conjunction with other catheter-based therapies such as thrombolysis or thrombectomy has not been evaluated in any high-quality randomized study. In a study from the national inpatient sample database, out of 7119 patients who underwent CDT for acute PE, nearly one third (34\%) underwent IVC filter placement. IVC filter placement did not result in lower in-hospital mortality or bleeding events, but was associated with higher rates of access site hematoma, in-hospital charges, and length of stay [40].

Based on the above evidence, we recommend the use of IVC filter in acute PE patients only in the setting of active bleeding. Routine IVC filter placement in acute PE patients receiving anticoagulation, thrombolysis, or undergoing other catheter-based therapies may not provide additional benefit but may result in higher rates of complications and increased cost of care. 
Fatality from acute PE is often the result of severe obstructive circulatory shock. Patients on the extreme end of the spectrum with very high pulmonary vascular thrombus burden remain at risk of imminent cardiac arrest. The term "catastrophic acute PE" can be collectively used to describe patients (1) who have suffered a cardiac arrest with or without (ongoing CPR) return of spontaneous circulation, or those (2) who remain at a very high risk of cardiac arrest such as shock refractory to ionotropic support or those who present with severe refractory hypoxemia.

The use of VA-ECMO in patients with catastrophic PE in conjunction with systemic fibrinolysis remains challenging due to a high rate of access site bleeding complications but is feasible. A retrospective study by Meneveau and colleagues [41] evaluated outcomes in 52 patients receiving ECMO in PE patients. Of these, 37 patients received ECMO support in conjunction with other therapies (fibrinolysis $=20$, embolectomy $=17$ ). The incidence of major bleeding was 39\% $(n=20)$. Although the incidence of bleeding was not reported in patients who received concomitant fibrinolytic therapy, it is plausible that this group remains at the highest risk of bleeding from large-bore access cannula placement for ECMO.

The evidence base for use of ECMO followed by catheter-directed thrombolysis is limited mostly to case reports or case series [42]. In a case series, which included 10 patients who required ECMO support for either cardiac arrest $(n=9)$ or refractory shock $(n=1)$, adjunctive catheter-based therapies were used in 9 patients and included catheter-directed thrombolysis, thrombectomy, or mechanical thrombus fragmentation or a combination. In this series, the 30-day mortality was 30\%. Apart from percutaneous catheter-based therapies, a surgical approach/ embolectomy is also feasible in patients on VA-ECMO support [43, 44].

ECMO support for patients with catastrophic PE sometimes may be the only management option available to patients in extremis. Veno-arterial ECMO (VAECMO) support in these patients provides hemodynamic stabilization and an opportunity to use interventions aimed at improving pulmonary vascular flow. Some patients may only need ECMO support till anticoagulation improves the pulmonary blood flow.

\section{Adjunctive pharmacotherapy}

Although catheter-based therapies have an important role in the management of patients with acute $\mathrm{PE}$, it should always be in the setting of adjunctive pharmacological therapy as tolerated on an individualized basis. In the following section, we discuss adjunctive pharmacotherapy with catheter-based therapies.

In patients undergoing CDT, anticoagulation with unfractionated or low molecular weight heparin (bivalirudin or argatroban for those with contraindication to heparin) should be considered universally. Patients who are felt to have contraindications to anticoagulation at initial presentation should be carefully evaluated during follow-up with initiation of anticoagulation when deemed feasible. A study showed that the majority of the patients in whom anticoagulation was perceived to be initially contraindicated were able to safely receive it [37]. 
For patients undergoing CDT, we recommend the use of low molecular weight heparin (LMWH) over unfractionated heparin (UFH) due to ease of use, predictable pharmacokinetics [45], and early achievement of a therapeutic anticoagulation effect. We recommend using $1 \mathrm{mg} / \mathrm{kg}$ body weight of enoxaparin $\mathrm{q} 12 \mathrm{~h}$ in patients with normal renal function. If UFH is used, we recommend maintaining PTT target 2-2.5 times the upper limit [46]. During the procedure, we recommend maintaining activated clotting time $>200 \mathrm{~ms}$ for patients who receive UFH prior to the procedure. For patients with the last dose of LMWH heparin at least $8 \mathrm{~h}$ prior to the procedure, intra-procedural anticoagulation can be achieved with UFH to maintain activated clotting time $>200 \mathrm{~ms}$. No additional intra-procedural anticoagulation may be needed for patients with the last dose of LMWH within $8 \mathrm{~h}$ of the procedure. Post-procedure, following a brief period of anticoagulation interruption $(<1 \mathrm{~h})$ for sheath removal, we recommend resuming therapeutic anticoagulation as soon as possible. In some patients, we may need to remove the sheaths while patients are fully anticoagulated.

Various dose protocols have been used for catheter-directed thrombolysis, depending on the device type. Doses in the range of 8-24 mg of tPA have been used in clinical trials. Recent trials have shown low-dose fibrinolytic dose may be equally effective in improving RV size and hemodynamics [15•]. We recommend lowering PTT target to 50-60 ms during infusion of the fibrinolytic agent in CDT. Once sheaths and catheters for CDT have been removed, we recommend a PTT target of 2-2.5 times the upper limit of normal.

\section{COVID-19-related acute PE and catheter-based therapies}

Studies have shown a higher incidence of acute PE in patients with COVID-19 pneumonia [47]. A French study of 107 consecutive patients presenting with COVID-19 pneumonia requiring ICU admission showed a 21\% incidence of acute $\mathrm{PE}$, which was much higher when compared to historical controls $(6.1 \%)$ [48] at the same institute in the pre-COVID era. Similar results were noted in other studies which showed a high incidence of acute PE in COVID-19 pneumonia patients [49-51].

Evidence for the use of catheter-based treatments in patients presenting with COVID-19-related acute PE is limited to case reports, with no studies systematically evaluating the outcomes in this group of patients [52-56]. Furthermore, the use of these devices in case reports is mostly limited to patients with highrisk PE, except in one case report where a patient with intermediate-risk acute PE was treated with thrombectomy using the FlowTriever catheter [54]. Although small in number, patients described in these case reports who received catheterbased treatments had successful outcomes, with improvement in hemodynamic status and oxygenation and successful weaning off from mechanical ventilatory support (Table 2 ). 


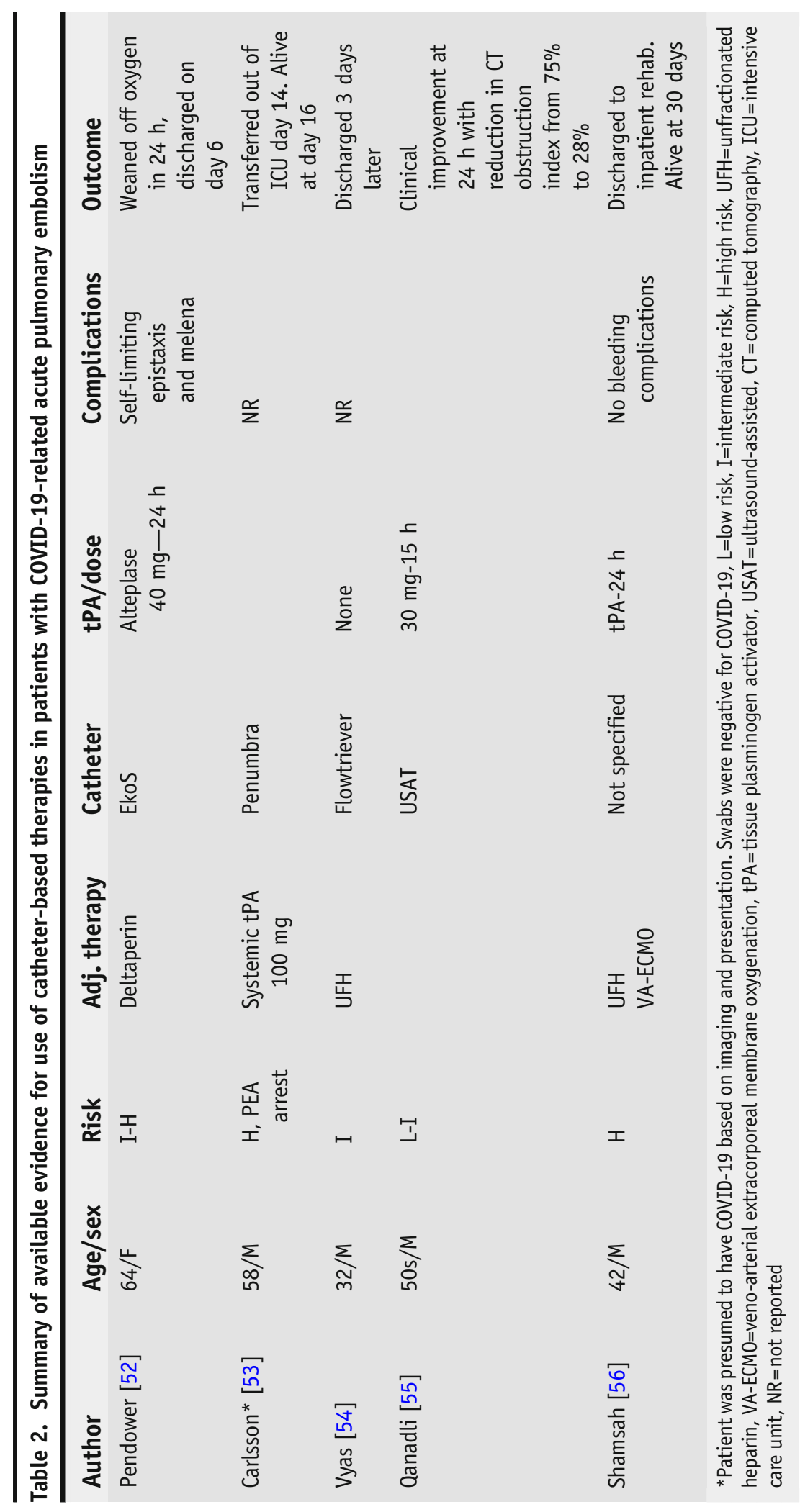


Apart from limited evidence of the use of standard catheter-based therapies for COVID-19-related acute PE patients, several other challenges remain. A recent study from New York showed nearly $40 \%$ lower Pulmonary Embolism Response Team (PERT) activations during the COVID-19 epidemic from March to April 2020 compared a similar time period a year earlier [57]. This was despite a higher number of acute PE patients treated during the same time period in 2020 at that institute. Despite the lower rate of activation of the PERT team, the recommendations and outcomes were similar to the pre-COVID-19 era in this study. Although the exact reasons for lower utilization of PERT are unclear from this study, it is conjectural that concerns with exposure to staff, higher use of resources, and personal protective equipment may have played a role in this. Another challenge in providing catheter-based therapies to eligible patients with COVID-19-related acute PE is the lack of consensus or clear recommendations from major societies. A recent CHEST guideline/expert panel report from June 2020 for treatment of venous thromboembolism in patients with COVID-19 recommends the use of thrombolytic agent delivery using a peripheral vein over catheterdirected thrombolysis [58]. However, this document neither provides any evidence for this recommendation nor it recommends any clinical situation where the use of catheter-based therapies may be preferred over systemic thrombolysis. It is plausible that this recommendation is mostly related to concerns about staff exposure. With the improvement in personal protective equipment shortages, and significant gain of experience in providing care to COVID-19 patients while minimizing

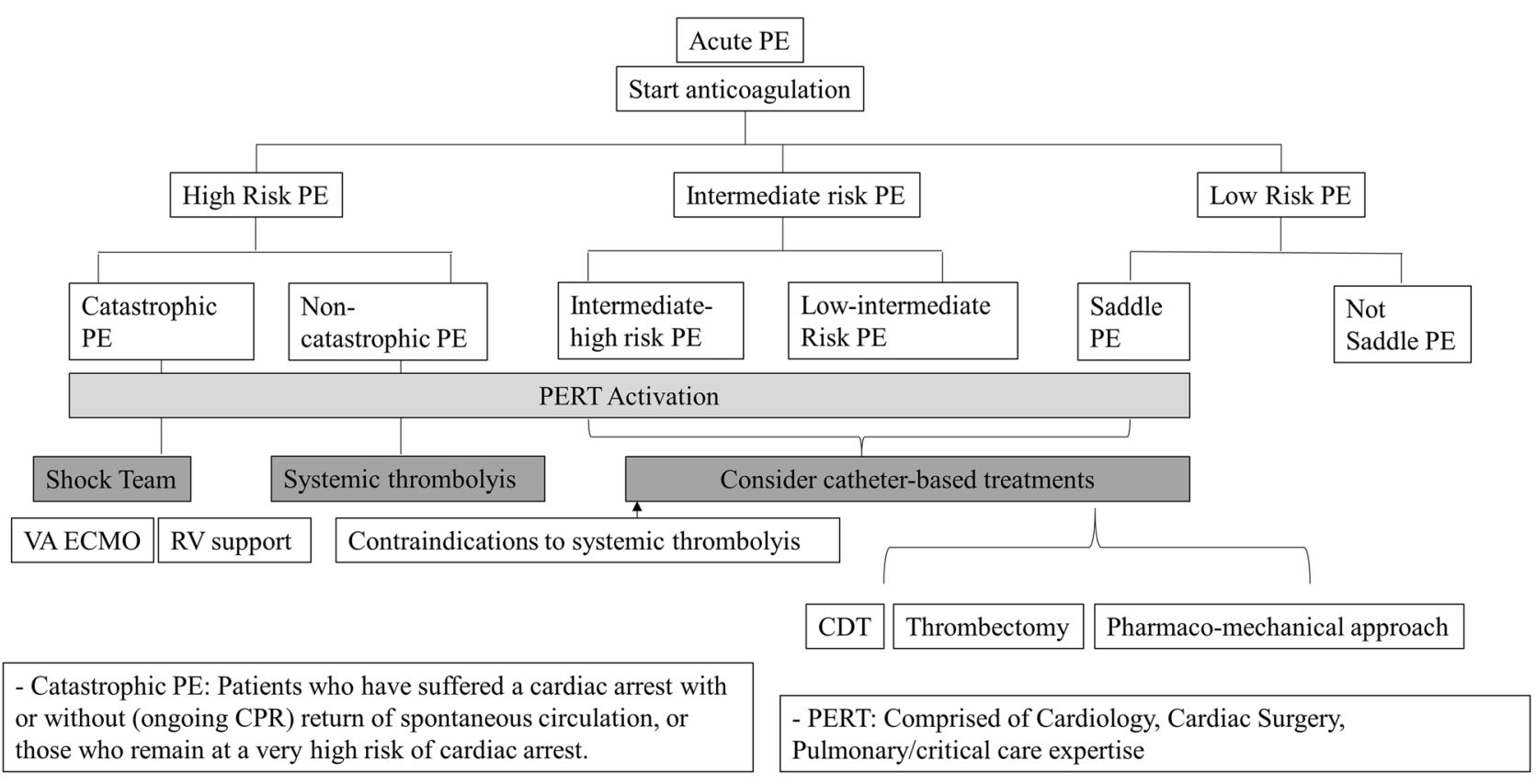

Fig. 2. Algorithm for management of patients with acute PE. PERT = pulmonary embolism response team, $C D T=$ catheter-directed thrombolysis, $\mathrm{VA}-\mathrm{ECMO}=$ veno-arterial extracoporeal membrane oxygenation, $\mathrm{RV}=$ right ventricular, $\mathrm{PE}=$ pulmonary embolism. 


\section{Future directions}

the risk of transmission, it is likely that the use of catheter-based therapies in patients with COVID-19 patients would have the same degree of benefit as in patients with non-COVID-19-related PE particularly by reducing the length of stay.

We hope that further evidence for treatment of these patients will become available from the PERT consortium COVID-19 PE registry [59], which is a nationwide registry currently enrolling patients to assess short-term and long-term outcomes of current treatments in COVID-19 patients with acute PE.

\section{Evidence base}

Evidence for use of new catheter-based devices is limited to relatively small single-arm studies with no control population. Larger randomized controlled studies are needed to better assess the efficacy of these devices. Most of the clinical trials included surrogate outcomes as the primary study end point. Although parameters like the RV/LV ratio, pulmonary artery pressures, or biomarkers have prognostic implications, more studies are needed to assess more meaningful end points like mortality, quality of life measures, functional capacity, and impact on chronic thromboembolic pulmonary hypertension. Hopefully, the PETRACT study will be funded by NIH and will attempt to answer this question.

Another important aspect to a successful implementation of catheterbased therapies and improving outcomes in patients presenting with acute PE patients is the adoption of a multidisciplinary approach (Fig. 2). Studies have shown improved outcomes with an approach of using the PERT concept [60, 61•]. We hope more hospital systems nationwide adopt the PERT model in the future which can further optimize the care of these patients.

\section{Conclusion}

With the improvement in catheter-based technologies and new designs, endovascular modalities have come to the forefront over the last few years and are now considered important therapeutic strategies for patients with intermediate-risk PE and many high-risk acute PE who are ineligible for systemic thrombolysis, where the risk of such therapy outweighs the benefits. While evidence for use of catheter-based therapies is growing, more studies are needed. Implementation of a multidisciplinary or PERT model is likely the best approach to appropriately select patients for these therapies. 


\section{Declarations}

Human and Animal Rights and Informed Consent

This article does not contain any studies with human or animal subjects performed by any of the authors.

\section{Conflict of Interest}

Dr. Riyaz Bashir has equity interest in Thrombolex Inc. Dr. Bashir receives research support from the NIH. Dr Maninder Singh: research grant and funding support from Donald Guthrie research foundation.

\section{References and Recommended Reading}

Papers of particular interest, published recently, have been highlighted as:

- Of importance

1. $\quad$ Corrigan D, Prucnal C, Kabrhel C. Pulmonary embolism: the diagnosis, risk-stratification, treatment and disposition of emergency department patients. Clin Exp Emerg Med [Internet]. The Korean Society of Emergency Medicine; 2016 [cited 2020 Sep 19];3:11725. Available from:/pmc/articles/PMC5065342/ ?report=abstract.

2. Turetz M, Sideris AT, Friedman OA, Triphathi N, Horowitz JM. Epidemiology, pathophysiology, and natural history of pulmonary embolism. Semin Intervent Radiol [Internet]. Thieme Medical Publishers, Inc.; 2018 [cited 2020 Sep 19];35:92-8. Available from: /pmc/articles/PMC5986574/?report=abstract.

3. Mackman N. Triggers, targets and treatments for thrombosis [Internet]. Nature. Nature Publishing Group; 2008 [cited 2020 Sep 6]. p. 914-8. Available from: /pmc/articles/PMC2848509/

? report $=$ abstract.

4. Scarvelis D, Wells PS. Diagnosis and treatment of deepvein thrombosis [Internet]. CMAJ. Canadian Medical Association; 2006 [cited 2020 Sep 6]. p. 1087-92. Available from: /pmc/articles/PMC1609160/ ?report=abstract.

5. Chatterjee S, Chakraborty A, Weinberg I, Kadakia M, Wilensky RL, Sardar P, et al. Thrombolysis for pulmonary embolism and risk of all-cause mortality, major bleeding, and intracranial hemorrhage: a meta-analysis. JAMA - J Am Med Assoc [Internet]. American Medical Association; 2014 [cited 2020 Sep 7];311:2414-21. Available from: https://pubmed.ncbi.nlm.nih.gov/ 24938564/

6. Quezada CA, Bikdeli B, Barrios D, Barbero E, Chiluiza D, Muriel A, et al. Meta-analysis of prevalence and short-term prognosis of hemodynamically unstable patients with symptomatic acute pulmonary embolism. Am J Cardiol [Internet]. Elsevier Inc.; 2019 [cited 2020 Sep 7];123:684-9. Available from: https://pubmed.ncbi.nlm.nih.gov/30528278/

7. Kearon C, Akl EA, Ornelas J, Blaivas A, Jimenez D, Bounameaux $\mathrm{H}$, et al. Antithrombotic therapy for VTE disease: CHEST guideline and expert panel report. Chest [Internet]. American College of Chest Physicians; 2016 [cited 2020 Sep 7];149:315-52. Available from: https://doi.org/10.1016/j.chest.2015.11.026

8. Meyer G, Vicaut E, Danays T, Agnelli G, Becattini C, Beyer-Westendorf $\mathrm{J}$, et al. Fibrinolysis for patients with intermediate-risk pulmonary embolism. N Engl J Med [Internet]. Massachussetts Medical Society; 2014 [cited 2020 Sep 7];370:1402-11. Available from: http://www.nejm.org/doi/10.1056/ NEJMoa1302097

9. Heit JA. The epidemiology of venous thromboembolism in the community [Internet]. Arterioscler. Thromb. Vasc. Biol. NIH Public Access; 2008 [cited 2020 Sep 7]. p. 370-2. Available from: https:// www.ncbi.nlm.nih.gov/pmc/articles/PMC2873781/

10. Konstantinides S, Geibel A, Heusel G, Heinrich F, Kasper W. Heparin plus alteplase compared with heparin alone in patients with Submassive pulmonary embolism. N Engl J Med [Internet]. Massachusetts Medical Society ; 2002 [cited 2020 Sep 7];347:1143-50. Available from: http://www.nejm. org/doi/abs/10.1056/NEJMoa021274

11. Giri J, Sista AK, Weinberg I, Kearon C, Kumbhani DJ, Desai ND, et al. Interventional therapies for acute pulmonary embolism: current status and principles for the development of novel evidence [Internet]. Circulation. Lippincott Williams and Wilkins; 2019 [cited 2020 Sep 13]. p. E774-801. Available from: http://ahajournals. org

12. EkoSonic ${ }^{\mathrm{TM}}$ Endovascular System - Boston Scientific [Internet]. [cited 2020 Sep 13]. Available from: https:// www.bostonscientific.com/content/gwc/en-US/ products/thrombectomy-systems/ekosonicendovascular-system.html

13. Piazza G, Hohlfelder B, Jaff MR, Ouriel K, Engelhardt TC, Sterling KM, et al. A Prospective, Singlearm, multicenter trial of ultrasound-facilitated, catheter-directed, low-dose fibrinolysis for acute massive and submassive pulmonary embolism: the 
SEATTLE II study. JACC Cardiovasc Interv [Internet]. Elsevier Inc.; 2015 [cited 2020 Sep 13];8:1382-92. Available from: https://pubmed. ncbi.nlm.nih.gov/26315743/

14. Kucher N, Boekstegers P, Müller OJ, Kupatt C, Beyer-Westendorf J, Heitzer T, et al. Randomized, controlled trial of ultrasound-assisted catheter-directed thrombolysis for acute intermediate-risk pulmonary embolism. Circulation [Internet]. Lippincott Williams \& WilkinsHagerstown, MD; 2014 [cited 2020 Sep 13];129:479-86. Available from: https://www.ahajournals.org/doi/10.1161/ CIRCULATIONAHA.113.005544

15. Tapson VF, Sterling K, Jones N, Elder M, Tripathy U, Brower J, et al. A randomized trial of the optimum duration of acoustic pulse thrombolysis procedure in acute intermediate-risk pulmonary embolism: the OPTALYSE PE trial. JACC Cardiovasc Interv [Internet]. Elsevier Inc.; 2018 [cited 2020 Sep 13];11:1401-10. Available from: https://pubmed.ncbi.nlm.nih.gov/ 30025734/.

This article provides a comparison of various dosing regimens of tPA for patients undergoing CDT. It provides a perspective of increase in bleeding complications with higher doses of tPA.

16. An International Pulmonary Embolism Registry Using EKOS - Full Text View - ClinicalTrials.gov [Internet]. [cited 2020 Sep 20]. Available from: https:// clinicaltrials.gov/ct2/show/NCT03426124

17. Uni* ${ }^{*}{ }^{\mathrm{TM}} \mathrm{T}^{\mathrm{I}}$ Infusion Catheter - AngioDynamics [Internet]. [cited 2020 Sep 13]. Available from: https://www. angiodynamics.com/products/36/Uni-Fuse-InfusionCatheter/

18. ev3, 41050-01, ev3 Cragg-McNamara valved infusion catheter $5 \mathrm{~F} \times 100 \mathrm{~cm} \times 10 \mathrm{~cm}$ - eSutures [Internet]. [cited 2020 Sep 13]. Available from: https://www.esutures. com/product/0-in-date/86-ev3/964-blood-clottherapy/46228377-ev3-cragg-mcnamara-valvedinfusion-catheter-5f-x-100cm-x-10cm-41050-01/

19. Rothschild DP, Goldstein JA, Ciacci J, Bowers TR. Ultrasound-accelerated thrombolysis (USAT) versus standard catheter-directed thrombolysis (CDT) for treatment of pulmonary embolism: a retrospective analysis. Vasc Med (United Kingdom) [Internet]. SAGE Publications Ltd; 2019 [cited 2020 Sep 13];24:234-40. Available from: http://journals. sagepub.com/doi/10.1177/1358863X19838350

20. Rao G, Xu H, Wang JJ, Galmer A, Giri J, Jaff MR, et al. Ultrasound-assisted versus conventional catheter-directed thrombolysis for acute pulmonary embolism: a multicenter comparison of patientcentered outcomes. Vasc Med (United Kingdom) [Internet]. SAGE Publications Ltd; 2019 [cited 2020 Sep 13];24:241-7. Available from: https://pubmed. ncbi.nlm.nih.gov/30915914/

21. Avgerinos ED, Mohapatra A, Rivera-Lebron B, Toma C, Kabrhel C, Fish L, et al. Design and rationale of a randomized trial comparing standard versus ultrasound-assisted thrombolysis for submassive pulmonary embolism. J Vasc Surg Venous Lymphat Disord [Internet]. Elsevier Inc.; 2018 [cited 2020 Sep 13];6:126-32. Available from: https://pubmed.ncbi.nlm.nih.gov/29248101/

22. Chauhan CA, Scolieri SK, Toma C. Percutaneous pulmonary embolectomy using the FlowTriever Retrieval/ Aspiration System. J Vasc Interv Radiol Elsevier Inc.; 2017. p. 621-3.

23. Tu T, Toma C, Tapson VF, Adams C, Jaber WA, Silver $\mathrm{M}$, et al. A Prospective, Single-Arm, multicenter trial of catheter-directed mechanical thrombectomy for intermediate-risk acute pulmonary embolism: the FLARE study. JACC Cardiovasc Interv [Internet]. Elsevier Inc.; 2019 [cited $2020 \mathrm{Sep}$ 19];12:859-69. Available from: https://pubmed. ncbi.nlm.nih.gov/31072507/

24. Penumbra Indigo Aspiration System IDE Trial for Acute Pulmonary Embolism Meets Primary Safety and Efficacy Endpoints | Cath Lab Digest [Internet]. [cited 2020 Sep 19]. Available from: https://www. cathlabdigest.com/content/penumbra-indigoaspiration-system-ide-trial-acute-pulmonaryembolism-meets-primary-safety-and-efficacyendpoints

25. Dudzinski DM, Giri J, Rosenfield K. Interventional treatment of pulmonary embolism. Circ Cardiovasc Interv [Internet]. Lippincott Williams and Wilkins; 2017 [cited 2020 Sep 19]; 10. Available from: https://pubmed.ncbi.nlm.nih.gov/28213377/

26. The Next Generation of Thrombus Removal | Penumbra Inc [Internet]. [cited 2021 Jan 1]. Available from: https://www.penumbrainc.com/indigo-lightning/

27. Chechi T, Vecchio S, Spaziani G, Giuliani G, Giannotti F, Arcangeli $\mathrm{C}$, et al. Rheolytic thrombectomy in patients with massive and submassive acute pulmonary embolism. Catheter Cardiovasc Interv [Internet]. John Wiley \& Sons, Ltd; 2009 [cited 2020 Sep 19];73:506-13. Available from: http:// doi.wiley.com/10.1002/ccd.21858

28. Kuo WT, Gould MK, Louie JD, Rosenberg JK, Sze DY, Hofmann L V. Catheter-directed therapy for the treatment of massive pulmonary embolism: systematic review and meta-analysis of modern techniques. J Vasc Interv Radiol. Elsevier; 2009;20:1431-40.

29. Schmitz-Rode T, Janssens U, Duda SH, Erley CM, Günther RW. Massive pulmonary embolism: percutaneous emergency treatment by pigtail rotation catheter. J Am Coll Cardiol [Internet]. Journal of the American College of Cardiology; 2000 [cited 2020 Sep 19];36:375-80. Available from: https:// www.onlinejacc.org/content/36/2/375

30. Bayiz H, Dumantepe M, Teymen B, Uyar I. Percutaneous aspiration thrombectomy in treatment of Massive pulmonary embolism. Hear Lung Circ [Internet]. Elsevier Ltd; 2015 [cited 2020 Sep 19];24:46-54. Available from: https://pubmed.ncbi.nlm.nih.gov/ 25060976/ 
31. Vedantham S, Goldhaber SZ, Julian JA, Kahn SR, Jaff MR, Cohen DJ, et al. Pharmacomechanical catheterdirected thrombolysis for deep-vein thrombosis. $\mathrm{N}$ Engl J Med [Internet]. Massachussetts Medical Society; 2017 [cited 2020 Sep 19];377:2240-52. Available from: http://www.nejm.org/doi/10.1056/ NEJMoa1615066

32. First patient enrolled in RESCUE trial of Thrombolex's Bashir catheter [Internet]. [cited 2020 Sep 19]. Available from: https://venousnews.com/first-patientenrolled-in-rescue-trial/

33. Sista $A K$, Bhatheja $R$, Rali $P$, Natarajan $K$, Green $P$, Piazza G, et al. First-in-human study to assess the safety and feasibility of the Bashir endovascular catheter for the treatment of acute intermediate-risk pulmonary embolism. Circ Cardiovasc Interv [Internet]. Lippincott Williams \& WilkinsHagerstown, MD; 2020 [cited 2021 Jan 1]; Available from: https://www.ahajournals.org/doi/10.1161/ CIRCINTERVENTIONS.120.009611

34. Mismetti P, Laporte S, Pellerin O, Ennezat PV, Couturaud F, Elias A, et al. Effect of a retrievable inferior vena cava filter plus anticoagulation vs anticoagulation alone on risk of recurrent pulmonary embolism: a randomized clinical trial. JAMA J Am Med Assoc [Internet]. American Medical Association; 2015 [cited 2020 Sep 27];313:1627-35. Available from: https://pubmed.ncbi.nlm.nih.gov/ 25919526/

35. Marron RM, Rali P, Hountras P, Bull TM. Inferior vena cava filters: past, present, and future [Internet]. Chest. Elsevier Inc.; 2020 [cited 2021 Jan 1]. p. 2579-89. Available from: https://pubmed.ncbi.nlm.nih.gov/ 32795479/

36. White RH, Brunson A, Romano PS, Li Z, Wun T. Outcomes after vena cava filter use in noncancer patients with acute venous thromboembolism. Circulation [Internet]. Lippincott Williams and Wilkins; 2016 [cited 2020 Sep 27];133:2018-29. Available from: https://pubmed.ncbi.nlm.nih.gov/ 27048765/

37. Gates K, Seiwert A, Kasper G, Wolff E, Lurie F. Outcomes of inferior vena cava filter placement in patients with perceived contraindications to anticoagulation. J Vasc Surg Venous Lymphat Disord [Internet]. Elsevier BV; 2020 [cited 2020 Sep 27];8:311. Available from: http://www.jvsvenous. org/article/S2213333X19306456/fulltext

38. Sarosiek S, Rybin D, Weinberg J, Burke PA, Kasotakis G, Sloan JM. Association between inferior vena cava filter insertion in trauma patients and inhospital \& overall mortality. JAMA Surg [Internet]. American Medical Association; 2017 [cited 2020 Sep 27];152:75-81. Available from: https:// pubmed.ncbi.nlm.nih.gov/27682367/

39. Kaufman JA, Barnes GD, Chaer RA, Cuschieri J, Eberhardt RT, Johnson MS, et al. Society of interventional radiology clinical practice guideline for inferior vena cava filters in the Treatment of patients with venous thromboembolic disease. J Vasc Interv Radiol [Internet]. SIR; 2020 [cited 2020 Sep 27];0:1-16. Available from: https://doi.org/10.1016/j.jvir.2020.06.014.

40. Akhtar OS, Lakhter V, Zack CJ, Hussain H, Aggarwal $\mathrm{V}$, Oliveros E, et al. Contemporary trends and comparative outcomes with adjunctive inferior vena cava filter placement in patients undergoing catheter-directed thrombolysis for deep vein thrombosis in the United States: insights from the national inpatient sample. JACC Cardiovasc Interv [Internet]. Elsevier Inc.; 2018 [cited 2020 Oct 11];11:1390-7. Available from: https:// pubmed.ncbi.nlm.nih.gov/30025732/

41. Meneveau N, Guillon B, Planquette B, Piton G, Kimmoun A, Gaide-Chevronnay L, et al. Outcomes after extracorporeal membrane oxygenation for the treatment of high-risk pulmonary embolism: a multicentre series of 52 cases. Eur Heart J [Internet]. Oxford University Press; 2018 [cited 2020 Oct 11];39:4196-204. Available from: https://academic.oup.com/eurheartj/ article/39/47/4196/5078171

42. Munakata R, Yamamoto T, Hosokawa Y, Tokita Y, Akutsu K, Sato N, et al. Massive pulmonary embolism requiring extracorporeal life support treated with catheter-based interventions. Int Heart J [Internet]. International Heart Journal Association; 2012 [cited 2020 Oct 11];53:370-4. Available from: https://www. jstage.jst.go.jp/article/ihj/53/6/53_370/_article

43. Goldberg JB, Spevack DM, Ahsan S, Rochlani Y, Dutta $\mathrm{T}$, Ohira S, et al. Survival and right ventricular function after surgical management of acute pulmonary embolism. J Am Coll Cardiol [Internet]. Elsevier USA; 2020 [cited 2020 Sep 27];76:903-11. Available from: https://doi.org/10.1016/j.jacc.2020.06.065.

44. Pasrija C, Kronfli A, George P, Raithel M, Boulos F, Herr DL, Gammie JS, Pham SM, Griffith BP, Kon $\mathrm{ZN}$ Utilization of veno-arterial extracorporeal membrane oxygenation for massive pulmonary embolism. 2018 [cited 2020 Sep 27]; Available from: https://doi.org/10.1016/j.athoracsur.2017. 08.033 .

45. Leentjens J, Peters M, Esselink AC, Smulders Y, Kramers C. Initial anticoagulation in patients with pulmonary embolism: thrombolysis, unfractionated heparin, LMWH, fondaparinux, or DOACs? [Internet]. Br. J. Clin. Pharmacol. Blackwell Publishing Ltd; 2017 [cited 2020 Oct 11]. p. 2356-66. Available from: /pmc/articles/PMC5651323/ ? report=abstract.

46. Alkhouli M, Morad M, Narins CR, Raza F, Bashir $R$. inferior Vena cava thrombosis [Internet]. JACC Cardiovasc. Interv. Elsevier Inc.; 2016 [cited 2020 Aug 22]. p. 629-43. Available from: http://www.acc.org/jaccjournals-cme

47. Jiménez D, García-Sanchez A, Rali P, Muriel A, Bikdeli $\mathrm{B}$, Ruiz-Artacho P, et al. Incidence of VTE and bleeding among hospitalized patients with coronavirus disease 2019. Chest [Internet]. Elsevier BV; 2020 [cited 2021 
Jan 1]; Available from: https://pubmed.ncbi.nlm.nih. gov/33217420/

48. Poissy J, Goutay J, Caplan M, Parmentier E, Duburcq T, Lassalle F, et al. Pulmonary embolism in patients with COVID-19: awareness of an increased prevalence [Internet]. Circulation. Lippincott Williams and Wilkins; 2020 [cited 2020 Sep 19]. p. 184-6. Available from: https://www. ahajournals.org/doi/10.1161/CIRCULATIONAHA. 120.047430

49. Bompard F, Monnier H, Saab I, Tordjman M, Abdoul H, Fournier L, et al. Pulmonary embolism in patients with COVID-19 pneumonia [Internet]. Eur Respir J European Respiratory Society; 2020 [cited 2020 Sep 19]. Available from:/pmc/articles/ PMC7236820/?report=abstract

50. Poyiadi N, Cormier P, Patel PY, Hadied MO, Bhargava $P$, Khanna $K$, et al. Acute pulmonary embolism and COVID-19. Radiology [Internet]. Radiological Society of North America (RSNA); 2020 [cited 2020 Sep 19];201955. Available from: http:// pubs.rsna.org/doi/10.1148/radiol.2020201955

51. Rali P, O'Corragain O, Oresanya L, Yu D, Sheriff O, Weiss $\mathrm{R}$, et al. Incidence of venous thromboembolism in coronavirus disease 2019: an experience from a single large academic center. J Vasc Surg Venous Lymphat Disord [Internet]. Elsevier Inc.; 2020 [cited 2021 Jan 1]; Available from: https:// pubmed.ncbi.nlm.nih.gov/32979557/

52. Pendower L, Benedetti G, Breen K, Karunanithy N. Catheter-directed thrombolysis to treat acute pulmonary thrombosis in a patient with COVID-19 pneumonia. BMJ Case Rep BMJ Publishing Group; 2020;13.

53. Carlsson TL, Walton B, Collin G. Pulmonary artery thrombectomy - a life-saving treatment in a patient with presumed COVID-19 complicated by a massive pulmonary embolus. Br J Haematol [Internet]. Blackwell Publishing Ltd; 2020 [cited 2020 Sep 19];190:e143-6. Available from: https:// onlinelibrary.wiley.com/doi/abs/10.1111/bjh. 16920

54. Vyas V, Kanagalingam G, Yadava S, Gambhir HS, Costanza M, Chaudhuri D. Bilateral pulmonary artery thrombectomy with saddle embolism and COVID-19 infection. Baylor Univ Med Cent Proc [Internet]. Taylor and Francis Inc.; 2020 [cited 2020 Sep 19];1-2. Available from: https://www. tandfonline.com/doi/full/10.1080/08998280.2020. 1799133

55. Qanadli SD, Gudmundsson L, Rotzinger DC. Catheter-directed thrombolysis in COVID-19 pneumonia with acute PE: thinking beyond the guidelines [Internet]. Thromb. Res. Elsevier Ltd;
2020 [cited 2020 Sep 19]. p. 9-11. Available from: /pmc/articles/PMC7205661/?report=abstract.

56. Shamsah MA, Bitar ZI, Alfoudri H. Right atrial thrombus in a patient with COVID-19 pneumonia: a case report. Tan TC, Sinning C, Sayers M, Ross T, editors. Eur Hear J - Case Reports [Internet]. 2020 [cited 2020 Sep 19]; Available from: https:// academic.oup.com/ehjcr/advance-article/doi/10. 1093/ehjcr/ytaa296/5901690

57. Kwok B, Brosnahan SB, Amoroso NE, Goldenberg RM, Heyman B, Horowitz JM, et al. Pulmonary embolism response team activation during the COVID-19 pandemic in a New York City Academic Hospital: a retrospective cohort analysis. J Thromb Thrombolysis [Internet]. Springer; 2020 [cited 2020 Sep 20];1. Available from: http://link.springer.com/ 10.1007/s11239-020-02264-8

58. Moores LK, Tritschler T, Brosnahan S, Carrier M, Collen JF, Doerschug K, et al. Prevention, diagnosis, and treatment of VTE in patients with coronavirus disease 2019: CHEST guideline and expert panel report. Chest [Internet]. Elsevier Inc; 2020 [cited 2020 Sep 20];158:1143-63. Available from: https://doi.org/10.1016/j.chest.2020.05.559.

59. Rosovsky RP, Davis GA, Lookstein R, And F, Rosenfield K. The PERT Consortium ${ }^{\circledR}$ COVID-19 PE Registry: introduction and implementation [Internet]. 2020 Jul. Available from: https://evtoday. com/pdfs/et0720_PERTSupp_sec2.pdf.

60. Chaudhury P, Gadre S, Schneider E, Renapurkar R, Gomes M, Haddadin I, et al. Impact of multidisciplinary pulmonary embolism response team availability on management and outcomes. Am J Cardiol [Internet]. Elsevier Inc.; 2019 [cited 2020 Sep 20];124:1465-9. Available from: http://www. ajconline.org/article/S0002914919308744/fulltext

61.• Rosovsky R, Chang Y, Rosenfield K, Channick R, Jaff MR, Weinberg I, et al. Changes in treatment and outcomes after creation of a pulmonary embolism response team (PERT), a 10-year analysis. J Thromb Thrombolysis [Internet]. Springer New York LLC; 2019 [cited 2020 Sep 20];47:31-40. Available from: https://link.springer.com/ article/10.1007/s11239-018-1737-8.

This article highlights the importance of a team-based approach in selecting appropriate therapy and device for patients with acute PE.

\section{Publisher's Note}

Springer Nature remains neutral with regard to jurisdictional claims in published maps and institutional affiliations. 